\title{
Evaluation of Three Devices for the Isolation of the Stromal Vascular Fraction from Adipose Tissue and for ASC Culture: A Comparative Study
}

\author{
Jonathan Rodriguez, ${ }^{1,2}$ Anne-Sophie Pratta, ${ }^{1}$ Nacira Abbassi, ${ }^{1}$ Hugo Fabre, ${ }^{3,4}$ \\ Fanny Rodriguez, ${ }^{1}$ Cyrille Debard, ${ }^{1}$ Jacqueline Adobati, ${ }^{5}$ Fabien Boucher, ${ }^{6}$ \\ Frédéric Mallein-Gerin, ${ }^{3}$ Céline Auxenfans, ${ }^{1}$ Odile Damour, ${ }^{1}$ and Ali Mojallal ${ }^{2,6}$ \\ ${ }^{1}$ Banque de Tissus et Cellules, Laboratoire des Substituts Cutanés, Hôpital Edouard Herriot, Hospices Civils de Lyon, 5 Place d’Arsonval, \\ Pavillon I, 69437 Lyon, France \\ ${ }^{2}$ Lyon University, CarMeN Laboratory, INSERM U1060, 69008 Lyon, France \\ ${ }^{3}$ Laboratoire de Biologie Tissulaire et Ingénierie Thérapeutique, UMR CNRS 5305, Université Lyon 1, Lyon, France \\ ${ }^{4}$ Laboratory for Regenerative Technologies, Department of Biomedical Engineering, University of Basel, 4123 Allschwil, Switzerland \\ ${ }^{5}$ Laboratoire Central d'Anatomie Pathologique, Hôpital Édouard Herriot, Lyon, France \\ ${ }^{6}$ Department of Plastic, Reconstructive and Aesthetic Surgery, Croix Rousse Hospital, Hospices Civils de Lyon, University of Lyon, \\ UCBL1, Lyon, France
}

Correspondence should be addressed to Jonathan Rodriguez; jrodriguez@jsei.ucla.edu

Received 19 July 2016; Accepted 13 December 2016; Published 22 February 2017

Academic Editor: Christian Dani

Copyright (C) 2017 Jonathan Rodriguez et al. This is an open access article distributed under the Creative Commons Attribution License, which permits unrestricted use, distribution, and reproduction in any medium, provided the original work is properly cited.

\begin{abstract}
Adipose-derived stem/stromal cells (ASCs) reside in the stromal vascular fraction (SVF) of adipose tissue (AT) and can be easily isolated. However, extraction of the SVF from lipoaspirate is a critical step in generating ASC, and semiautomated devices have been developed to enhance the efficacy and reproducibility of the outcomes and to decrease manipulation and contamination. In this study, we compared the reference method used in our lab for SVF isolation from lipoaspirate, with three medical devices: GID SVF$1^{\mathrm{TM}}$, Puregraft ${ }^{\mathrm{TM}}$, and Stem.pras ${ }^{\circledR}$. Cell yield and their viability were evaluated as well as their phenotype with flow cytometry. Further on, we determined their proliferative potential using population doublings (PD), PD time (PDT), and clonogenicity assay (CFUF). Finally, we checked their genetic stability using RT-qPCR for TERT mRNA assay and karyotyping as well as their multilineage potential including adipogenic, chondrogenic, and osteogenic differentiation. Our results demonstrate that all the devices allow the production of SVF cells with consistent yield and viability, in less time than the reference method. Expanded cells from the four methods showed no significant differences in terms of phenotype, proliferation capabilities, differentiation abilities, and genetic stability.
\end{abstract}

\section{Introduction}

For many years, subcutaneous adipose tissue (AT) has been used for plastic and aesthetic surgery indications such as lipofilling and breast augmentation $[1,2]$. However, the mechanism by which fat is able to stay at the site of injection was not fully understood. It is admitted that mesenchymal stem cells (MSCs) found in AT, that is, adipose-derived stromal cells (ASC) $[3,4]$, could be responsible for the engraftment success. Therefore, cell-assisted lipotransfer (CAL) has been developed to enrich the graft with SVF or ASC [5-7]. Nevertheless, this approach needs the isolation of the stromal vascular fraction (SVF) in the operating room, while the patient is under anesthesia. The reference method to isolate the SVF [4] is based on the series of washing, centrifugation, and collagenase digestion in a completely open system that is time-consuming and thus cannot be performed in operating room. Accordingly, companies have developed or are developing devices in order to provide an easy, fast, reliable, and closed system to isolate this SVF at the point of care [8-10]. 
These devices allow, on one hand, both the SVF extraction to be used to enrich the adipose tissue before grafting and, on the other hand, ASC isolation for expansion in GMP facilities for their use in the field of regenerative medicine.

ASC and all the MSCs share the same multilineage properties as their counterpart in the bone marrow [3, 4, 11, 12]. The Mesenchymal and Tissue Stem Cell Committee of the International Society for Cellular Therapy (ISCT) has proposed a minimal set of three criteria to define human MSCs [13] which have been recently updated [14]. Both SVF cells and cultured ASC have shown great promise in various therapeutic fields such as wound healing $[15,16]$, scleroderma $[17,18]$, osteoarthritis [19], erectile dysfunction [20], multiple sclerosis [21], and renal insufficiency [22] and numerous clinical trials are being conducted with the use of SVF or ASC (https://clinicaltrials.gov/).

The main goal of this study was to validate three devices allowing the isolation of the SVF for usage both in operating room for CAL purposes and in GMP facilities for advancedtherapy medicinal product (ATMP) development. In order to be confident to the current good manufacturing practices (cGMP) guidelines for the production of an ATMP, our criteria were the extraction yield, proliferation capabilities, multilineage potential, immunophenotype, and genetic stability. We therefore evaluated three medical devices: GIDSVF1 is already CE-labeled for SVF extraction; Puregraft is a fat bag allowing the washing and filtration of lipoaspirated fat and these inner properties were used in this study to isolate SVF; and Stem.pras is a device in development that we compared to the reference method regarding SVF cell yield and viability and phenotype, proliferation, multipotentiality, and genetic stability of cultured ASC.

\section{Materials and Methods}

2.1. Patients Selection. Surgical residue harvesting was performed according to French regulation including declaration to research ministry (DC number 2008162) and written information consent of the patients. The adipose tissue was harvested from the abdomen of 4 healthy donors undergoing an abdominal tumescent liposuction for cosmetic purpose. The mean age and BMI were $36.8 \pm 5.13$ (range 22-49) and $31.1 \pm 2.41$ (range 24.7-37.7) (mean \pm SEM, $n=4$ ), respectively.

2.2. Tissue Collection. For reference method and Puregraft, Adipose tissue was harvested via a $3 \mathrm{~mm}$ blunt cannula using a liposuction pump at $-300 \mathrm{mmHg}$. Fat tissue was collected in a canister from where it was transferred to $60 \mathrm{cc}$ syringes and then injected to the Puregraft filtration bag. For reference method, the canister was sent to the lab without additional manipulation within the operating room.

For Stem.pras and GID-SVF1, fat was harvested via a $3 \mathrm{~mm}$ blunt cannula using a liposuction pump at $-300 \mathrm{mmHg}$ in a closed system. The vacuum pump was connected into the device and the suction tube came from the device to the harvesting cannula. After suctioning, the fat was directly collected in the device without any manipulation for Stem.pras. For GID-SVF1, an additional filtration system allows the immediate separation of the fluid part from the collected fat.

2.3. Medical Devices Description (See Table 1 and Figure 1). Available devices for SVF isolation were screened and three systems were selected according to several criteria (Table 1). The devices had to be convenient for its use in a surgical unit and GMP facilities and to provide viable cells with a yield not significantly different than reference method and provide genetically stable ASC cells meeting ISCT criteria:

(1) GID-SVF1 (Figure 1(a)) is from GID Europe. This CEmarked tool is designed to isolate the SVF cells from human lipoaspirate up to $350 \mathrm{~g}$ of dry adipose tissue (free of fluids). It enables the harvest of patient's lipoaspirate straight into the device, in a closed/safe sterile system, which allows direct filtration for separation of adipose tissue from its lipoaspirate fluids. It requires the use of GIDzyme-2 provided in the ready-to-use kit, a mix of collagenase optimized to dissociate the adipose tissue.

(2) Puregraft 250 (Figure 1(b)) is a purifying fat bag designed to wash and filter the fat before getting injected. Puregraft drains the tumescent fluid, free lipid, blood cells, and excess fluid from the graft [23]. In this study, we used its inner properties to design a new method to isolate SVF cells (see description below). Fat has to be harvested in an intermediate canister and then to be injected in the bag for filtration.

(3) Stem.pras with Duografter II ${ }^{\circledR}$ (Figure 1(c)) from Proteal ${ }^{\circledR}$ provides a kit allowing the harvest of the fat and the isolation of SVF cells straight inside. It is designed as $50 \mathrm{cc}$ canister (up to 4 canisters available in the kit) where fat can be harvested and then the canister is centrifuged. This device is not yet commercially available as we tested a prototype in development.

2.4. Lipoaspirate Processing. Each lipoaspirate from all patients was processed with all the devices.

The collagenase (NB6 GMP-grade, Serva Electrophoresis, Heidelberg, Germany) was used at a final concentration of $0.1 \mathrm{U} / \mathrm{mL}$, except for GID-SVF1, as the manufacturer recommends the use of the GIDzyme-2.

Washing steps and digestion have been carried out using lactated Ringer (LR) solution $\left(130 \mathrm{mmol} / \mathrm{L} \mathrm{Na}^{+}, 109 \mathrm{mmol} / \mathrm{L}\right.$ $\mathrm{Cl}^{-}, 28 \mathrm{mmol} / \mathrm{L}$ lactate, $1.5 \mathrm{mmol} / \mathrm{L} \mathrm{Ca}^{2+}, 4 \mathrm{mmol} / \mathrm{L} \mathrm{K}^{+}$).

Tissue processing to obtain stromal vascular fraction was performed concurrently in all four systems.

2.4.1. Reference Method. The SVF isolation was performed according to previously published method, with slight modifications [4]. Briefly, adipose tissue (Figure 1(d)) was washed 3 times in $20 \mathrm{~mL}$ syringes to remove lipoaspirate fluids, weighed, and then digested in $\operatorname{LR}(1: 1, \mathrm{v} / \mathrm{v}$, fat/LR) containing collagenase NB6 at a final concentration of $0.1 \mathrm{U} / \mathrm{mL}$ at $37^{\circ} \mathrm{C}$ for $45 \mathrm{~min}$ and under constant shaking. Digestion 


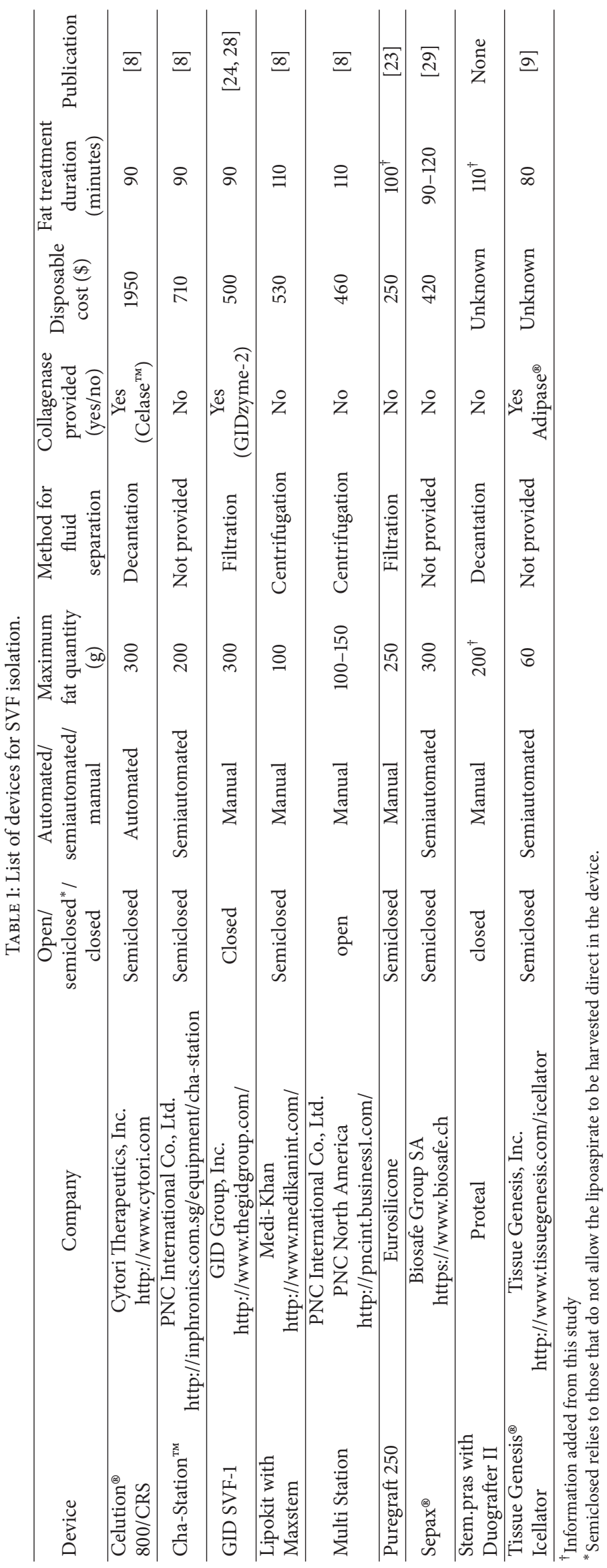




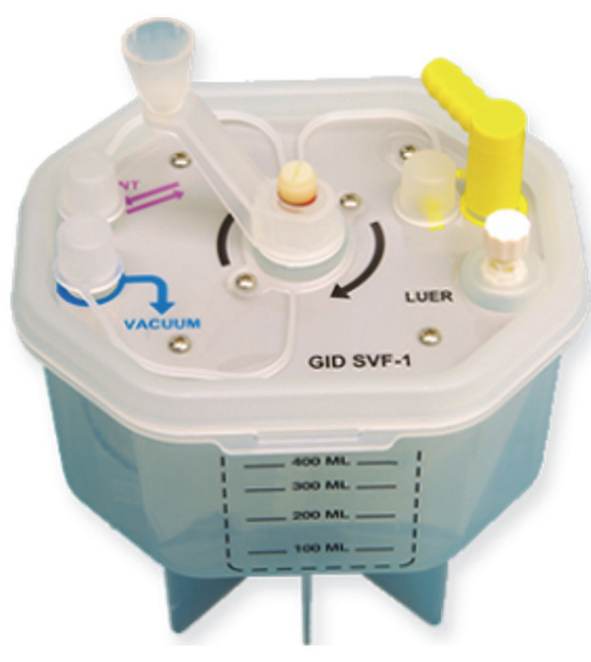

(a)

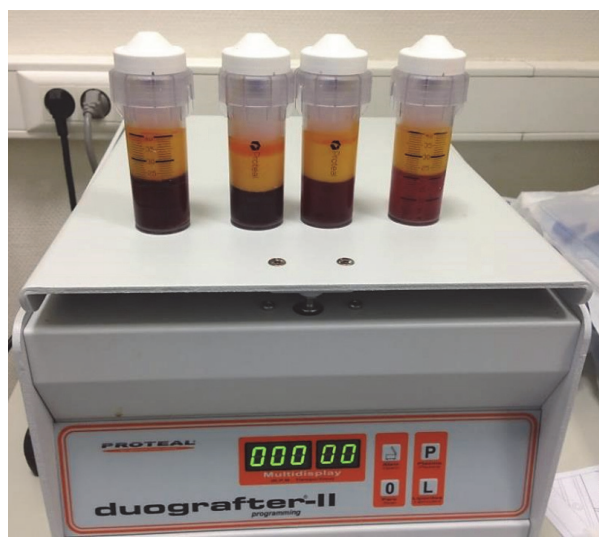

(c)

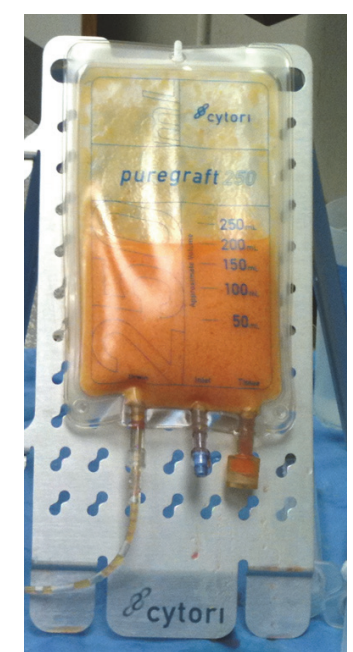

(b)

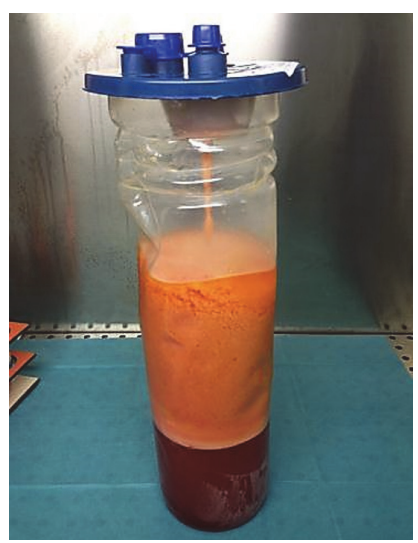

(d)

FIgURE 1: Devices used for comparative SVF isolation. (a) GID-SVF1. (b) Puregraft 250. (c) Stem.pras. (d) Reference method.

was stopped by adding Dulbecco's Modified Eagle's Medium (DMEM with GlutaMAX ${ }^{\mathrm{TM}}, \mathrm{Gibco}^{\circledR}$, Carlsbad, USA) containing $10 \%$ fetal calf serum (FCS, HyClone, Thermo Fisher Scientific, Waltham, Massachusetts, USA). After centrifugation at $300 \mathrm{~g} \cdot \mathrm{min}^{-1}$ for $5 \mathrm{~min}$, floating adipocytes were discarded and cells from the SVF were pelleted, rinsed with media, centrifuged $\left(300 \mathrm{~g} \cdot \mathrm{min}^{-1}\right.$ for $\left.5 \mathrm{~min}, 20^{\circ} \mathrm{C}\right)$, and filtered through a $70 \mu \mathrm{m}$ sieve. Red blood cells (RBC) count was performed using a Pentra 60C+ (Horiba Medical, Kyoto, Japan). Cell pellet was then incubated in an erythrocyte lysis buffer (Hybri-Max ${ }^{\mathrm{TM}}$, Sigma-Aldrich, Saint-QuentinFallavier, France) for $20 \mathrm{~min}$ at $37^{\circ} \mathrm{C}$. This cell suspension was centrifuged and total nucleated cells (TNC) were counted using Trypan blue exclusion method.

2.4.2. Other Methods Using Medical Devices. For GID-SVF1, fat was collected in the device and isolation was performed as described previously [24]. After the third washing, the device was weighed to determine the total adipose tissue mass (GIDSVF1 tare was $254 \mathrm{~g}$ ). For digestion, the fat was suspended in LR, to which an appropriate collagenase mix (GIDzyme-2 suspended in LR) was added. As recommended by the manufacturer, LR and the GIDzyme addition was adjusted to the amount of fat collected, with 1 vial for $100-175 \mathrm{~g}$ of fat. The device was incubated at $37^{\circ} \mathrm{C}$ for 45 minutes on a shaking rocker. The collagenase reaction was stopped by adding FCS in the device. The entire device was centrifuged for 10 minutes at $800 \mathrm{~g} \cdot \mathrm{min}^{-1}$ and the oil layer removed. Using the manufacturer's protocol, the pellet was resuspended in LR and additional washes were performed after removal of the oil layer. After a second centrifugation, the remaining supernatant was removed and the pellet transferred to a $50 \mathrm{~mL}$ conical tube for the red blood cell numeration and the subsequent RBC lysis as described above.

For the Puregraft 250, fat was collected in an intermediate sterile canister and then transferred into the bag using a Toomey syringe. LR was injected into the bag using the "inlet" site to wash the lipoaspirate and contaminant fluids were removed using the "waste" site. After three washings, the bag was weighed to determine the total adipose tissue mass (Puregraft tare was $45 \mathrm{~g}$ ). For digestion, the fat was suspended in LR ( $1: 1, \mathrm{v} / \mathrm{v}$, fat/LR), and collagenase NB6 was added at 
a final concentration of $0.1 \mathrm{U} / \mathrm{mL}$. The device was incubated at $37^{\circ} \mathrm{C}$ for 45 minutes on a shaking rocker. The collagenase reaction was stopped by adding serum-containing medium. Then, tissue lysate was collected via the waste site, leaving remnant extracellular matrix in the bag, and transferred into $50 \mathrm{~mL}$ conical tube which was spun down at $300 \mathrm{~g} \cdot \mathrm{min}^{-1}$ for $5 \mathrm{~min}$. Floating adipocytes were discarded and cells from the SVF were pelleted, rinsed with media, centrifuged, $70 \mu \mathrm{m}$ sieve filtered, and incubated in an erythrocyte lysis buffer for $20 \mathrm{~min}$ at $37^{\circ} \mathrm{C}$. This cell suspension was centrifuged and TNC were counted using Trypan blue exclusion method. Red blood cells count was performed using a Pentra 60C+.

For Stem.pras, fat was collected in four canisters as described above and LR was injected into each canister using the injection site to wash the lipoaspirate and contaminant fluids were removed using the same site. After three washings, the canisters were weighed to determine the total adipose tissue mass (canister tare was $45.5 \mathrm{~g}$ ). For digestion, the fat was suspended in LR (1:1,v/v, fat/LR), and collagenase NB6 was added at a final concentration of $0.1 \mathrm{U} / \mathrm{mL}$. The canisters were incubated at $37^{\circ} \mathrm{C}$ for 45 minutes on a shaking rocker. The collagenase reaction was stopped by adding serumcontaining medium. Then, the canisters were spun down at $300 \mathrm{~g} \cdot \mathrm{min}^{-1}$ for $5 \mathrm{~min}$ and floating adipocytes were suctioned with a syringe. Finally, cells from the SVF were collected, rinsed with media, centrifuged, and filtered through a $70 \mu \mathrm{m}$ sieve. RBC counting was performed as described above. Cell pellet was then incubated in an erythrocyte lysis buffer for $20 \mathrm{~min}$ at $37^{\circ} \mathrm{C}$. This cell suspension was centrifuged and TNC were counted using Trypan blue exclusion method.

\subsection{Evaluation Criteria}

2.5.1. Processing Time. Isolation was performed within two hours after tissue collection and fat was kept at room temperature until then. Processing time was approximately evaluated from the beginning of the isolation (first wash) to the obtaining of SVF (end of red blood cell lysis).

2.5.2. SVF Cell Yield. SVF yield was calculated by dividing the number of viable TNC in SVF per gram of processed fat (i.e., dry fat weighed for collagenase digestion). Data are expressed as number of viable cells $\times 10^{6} / \mathrm{g}$ of dry fat \pm standard error of the mean (SEM).

\section{Cultured ASC Characterization}

(1) Phenotype. SVF and the two subsequent subculture (named as P0 and P1) cells were characterized for their phenotype using flow cytometry approach. Briefly, after detachment, cells were resuspended in PBS at a concentration of 12 millions/mL. $100 \mu \mathrm{L}$ of this cell suspension was stained in PBS using FITC-coupled CD105, CD45, HLA-ABC and PEcoupled CD90, CD73, CD14, CD34, and HLA-DR antibodies (all from BD Biosciences, Le Pont de Claix, France). Fifty thousand events were acquired with a FACS Canto II (BD Biosciences) and analyzed (DIVA software) against appropriate isotypic controls.
(2) Proliferation Capabilities and Clonogenic Potential (CFU-F Assay)

Proliferation was assessed as follows: freshly isolated SVF cells from the four techniques were plated at 40,000 cells $/ \mathrm{cm}^{2}$ and cultured at $37^{\circ} \mathrm{C}$ in an atmosphere of $5 \%$ of carbon dioxide in humid air. Medium was replaced one hour after plating in order to remove nonadherent cells [23]. Proliferation medium was DMEM/F12 with GlutaMAX, 10\% FCS, $100 \mathrm{U} / \mathrm{mL}$ penicillin, $100 \mu \mathrm{g} / \mathrm{mL}$ gentamicin, $5 \mu \mathrm{g} / \mathrm{mL}$ fungizone, and $10 \mathrm{ng} / \mathrm{mL}$ FGF2 premium grade (Miltenyi Biotec, Paris, France). Medium was replaced every 2-3 days and cells were detached at subconfluency using Trypsin-EDTA and replated at a density of $4,000 \mathrm{cell} / \mathrm{cm}^{2}$. The amount of population doubling (PD) was calculated as follows: $\mathrm{PD}=\log (\mathrm{N} / \mathrm{N} 0)$ / $\log 2$, where $N 0$ is the seeded cell number and $N$ the harvested cell number. The doubling time (DT) was calculated by dividing the PD by the number of hours between seeding time and detachment of the cells.

Clonogenic potential was assessed as follows: cells recovered from the different devices were seeded at low density $\left(40\right.$ cells $\left./ \mathrm{cm}^{2}\right)$ in triplicate in proliferation medium described above. Colonies were grown for 10 to 14 days, depending on the growth rate of the cells. At the end of the assay, the culture dishes were rinsed with phosphate-buffered saline twice and then fixed with $10 \%$ neutral buffered formalin for 20 minutes and then stained with $0.5 \%$ crystal violet (Sigma-Aldrich, Saint-Quentin-Fallavier, France). Cell colonies were counted using phase contrast microscopy. All three Petri dishes were counted, and the average and standard deviation were calculated to generate the final frequency percentage value expressed as colony forming efficiency (CFE) by dividing the number of colony counted by the number of cells seeded $\times 100$.

(3) Genetic Stability. For karyotyping analysis, cells expanded at passage 1 were exposed for 3 hours to $0.7 \%$ colcemid (Life Technologies) diluted in the culture medium, and then cells were detached and centrifuged. The pellet was then resuspended in $0.075 \mathrm{~mol} / \mathrm{L} \mathrm{KCl}$ for 2 minutes at room temperature. Cells were centrifuged again, resuspended in methanol acetic acid $(3: 1)$ fixative, and stored at $-20^{\circ} \mathrm{C}$ for at least 2 days. G-band staining was performed with the Leishman-Giemsa cocktail.

For TERT mRNA expression assay, RT-qPCR (see details below) was performed on cells expanded at passage 1 . As positive control, MRC5-TERT cell line (cell line number 617, CelluloNet BioBank BB-0033-00072) transfected with LentiTERT virus (Cat number G200, ABM, Richmond, Canada) and the same untransfected cell line MRC5 (cell line number 494, CelluloNet BioBank BB-0033-00072) were used.

(4) Multipotency. For adipogenic differentiation, confluent cells at passage 1 were induced using adipogenic medium 
TABLE 2: List of primers used for RT-qPCR experiments.

\begin{tabular}{|c|c|c|c|c|c|}
\hline Gene name & $\begin{array}{c}\text { Alternative } \\
\text { name }\end{array}$ & $\begin{array}{c}\text { Accession } \\
\text { numbers }\end{array}$ & Forward $5^{\prime}-3^{\prime}$ & Reverse $5^{\prime}-3^{\prime}$ & Size $(b p)$ \\
\hline GUSB & & NM_000181 & TGGTTGGAGAGCTCATTTGG & CTCTCGCAAAAGGAACGCTG & 131 \\
\hline TERT & & $\begin{array}{c}\text { NM_001193376 } \\
\text { NM_198253 }\end{array}$ & GCACCAACATCTACAAGATCC & GACATCCCTGCGTTCTTGGC & 181 \\
\hline LEP & OB & NM_008493 & CACCAGGATCAATGACATTTC & TGCCAGTGTCTGGTCCATCTTG & 124 \\
\hline PPARG & & $\begin{array}{c}\text { NM_138711 } \\
\text { NM_015869 } \\
\text { NM_005037 } \\
\text { NM_138712 }\end{array}$ & TCTCTCCGTAATGGAAGACC & GCATTATGAGACATCCCCAC & 474 \\
\hline RUNX2 & & $\begin{array}{l}\text { NM_001015051 } \\
\text { NM_001024630 } \\
\text { NM_001278478 } \\
\end{array}$ & ACCAGATGGGACTGTGGTTAC & AGACGGTTATGGTCAAGGTG & 167 \\
\hline ALPL & $\mathrm{AP}$ & $\begin{array}{c}\text { NM_000478 } \\
\text { NM_001127501 } \\
\text { NM_001177520 } \\
\end{array}$ & GACCTCGTTGACACCTGGAAG & TTCCTGTTCAGCTCGTACTGC & 155 \\
\hline SOX9 & & NM_000346.3 & CCCAACGCCATCTTCAAGG & GGTCAAACTCGTTGACATCG & 289 \\
\hline COL2A1 & & $\begin{array}{l}\text { NM_001844 } \\
\text { NM_033150 }\end{array}$ & TCCATGTTGCAGAAAACCTTCA & GGAAGAGTGGAGACTACTGGATTGAC & 76 \\
\hline ACAN & $\mathrm{AGC1}$ & $\begin{array}{l}\text { NM_001135 } \\
\text { NM_013227 }\end{array}$ & TCGAGGACAGCGAGGCC & TCGAGGGTGTAGCGTGTAGAGA & 85 \\
\hline
\end{tabular}

consisting of DMEM supplemented with $10 \%$ of FCS, $10 \mu \mathrm{g} / \mathrm{mL}$ of 3 -isobutyl-1-methylxanthine (IBMX), $100 \mu \mathrm{M}$ of indomethacin, $0.1 \mu \mathrm{M}$ of dexamethasone (All from SigmaAldrich, Saint-Quentin-Fallavier, France), and $200 \mathrm{mUI}$ of insulin (Umulin, Lilly laboratories, Neuilly-sur-Seine, France). After 14 days, lipid droplets were stained using $0.4 \%$ Oil Red O solution after $10 \%$ formalin fixation, and total mRNA were harvested using RLT buffer and treated as described below (cf. RT-qPCR assay).

For osteogenic differentiation, subconfluent cells at passage 1 were induced using StemPro ${ }^{\circledR}$ Osteogenesis Differentiation Kit $\left(\mathrm{Gibco}^{\circledR}\right.$, Life Technologies, St Aubin, France). After 3 weeks, cells were fixed and stained with $40 \mathrm{mM}$ Alizarin Red (Merck Millipore, Fontenay-sous-Bois, France) to visualize calcium deposition, and total mRNA were harvested using RLT buffer and treated as described below (cf. RT-qPCR assay).

Chondrogenic differentiation was evaluated using highdensity pellet culture approach as previously described [25]. Briefly, subconfluent cells at P1 were detached using TrypsinEDTA, numerated and $3.5 \times 10^{5}$ viable ASCs were centrifuged $(300 \mathrm{~g}, 10 \mathrm{~min}, 2$ times) in a V-bottom 96-well plate (BD Biosciences) to form a pellet. The pellets were treated for 21 days with defined chondrogenic medium, which consisted of DMEM-F12 (4.5 g/L glucose, Life Technologies, St Aubin, France), 1\% of Insulin-Transferrin-Selenium (ITS, Life Technologies, St Aubin, France), 100 nM dexamethasone, $170 \mu \mathrm{M}$ L-ascorbic acid-2-phosphate, $1 \mathrm{mM}$ sodium pyruvate, $350 \mu \mathrm{M}$ L-prolin, $10 \mathrm{ng} / \mathrm{mL}$ of transforming growth factor $\beta 3$ (TGF $\beta 3$, R\&D Systems, Minneapolis, USA), and $50 \mathrm{ng} / \mathrm{mL}$ of bone morphogenetic protein (BMP2, Inductos, Medtronic Biopharma). On day 21, the pellet was harvested and fixed in $10 \%$ buffered formalin before embedding in paraffin. For histological analysis, tissue sections $(3 \mu \mathrm{m})$ were deparaffinized and rehydrated and chondrogenic differentiation was assessed by Alcian Blue staining of sulfated proteoglycans. Total mRNA were harvested from at least five pooled cell pellets using RLT buffer and treated as described below (cf. RT-qPCR assay).

2.6. RT-qPCR Assay. Tips and tubes for RT-qPCR were purchased from Sarstedt (Nümbrecht, Germany). Total RNA were extracted using RNeasy mini kit (Qiagen, Courtaboeuf, France) and assessed with NanoQuant system (Infinite ${ }^{\circledR} 200$ Pro, Tecan, Männedorf, Suisse). cDNAs were first synthesized from $500 \mathrm{ng}$ of total RNA in the presence of PrimeScript ${ }^{\mathrm{TM}}$ RT (PrimeScript RT Reagent Kit, Takara Biotechnology, Shiga, Japan), 25 pmol of Oligo dT primers, and $200 \mathrm{pmol}$ of random hexamers. RT products were treated with 60 units of Ribonuclease H (Takara Biotechnology). The real-time PCR was performed using a RotorGene 6000 (Corbett Research, Mortlake, Australia) in a final volume of $20 \mu \mathrm{L}$ containing $5 \mu \mathrm{L}$ of a 60 -fold dilution of the RT reaction medium, $15 \mu \mathrm{L}$ of reaction buffer from the Absolute qPCR SYBR ${ }^{\circledR}$ Green ROX Mix (Thermo Fischer Scientific), and $7.5 \mathrm{pmol}$ of the specific forward and reverse primers (Sigma-Aldrich, Saint-QuentinFallavier, France). Primers were selected in order to span two different exons separated by an intron of at least $1 \mathrm{kbp}$ so that genomic DNA contamination is of no concern (see Table 2).

Total amount of mRNA was normalized to endogenous GUSB mRNA that has been shown to be stable in culture and differentiation of ASC $[26,27]$. Each assay was performed in duplicate and validation of the real-time PCR runs was assessed by evaluating the melting temperature of the products. mRNA relative quantification was done using $2^{-\Delta \Delta C t}$ 


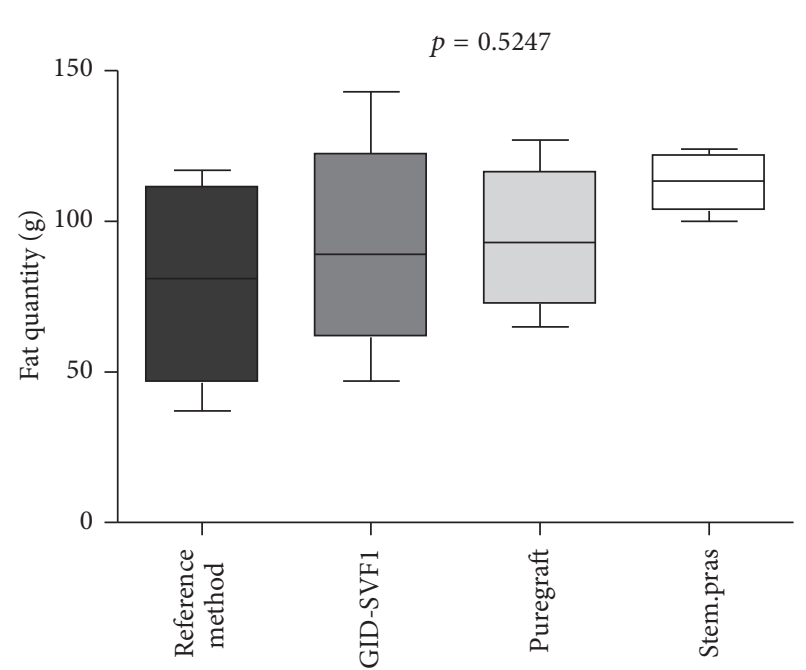

(a)

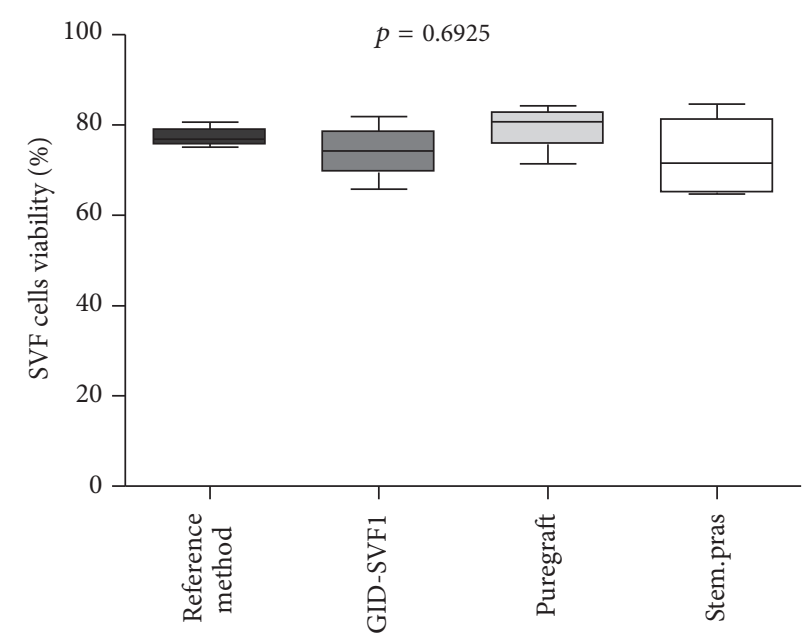

(c)

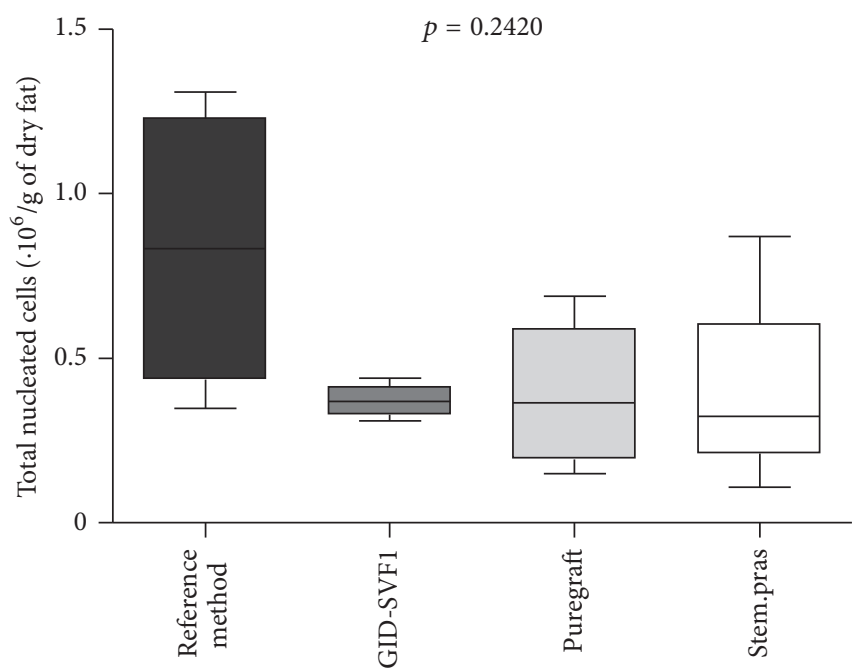

(b)

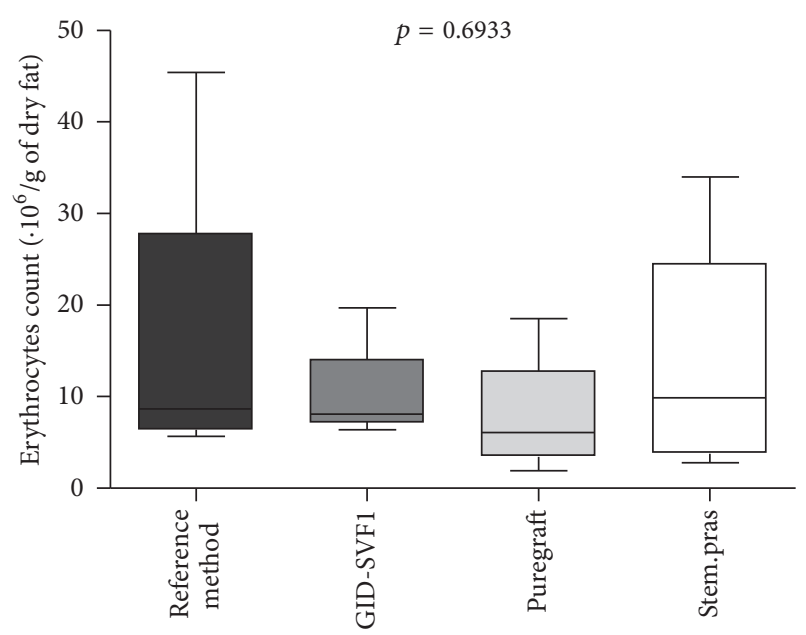

(d)

FIGURE 2: Fat quantity for the isolation, TNC count and their viability, and erythrocytes number remaining in the SVF. (a) Fat quantity (in grams) obtained after washing steps and therefore used for collagenase digestion. (b) Total nucleated cells obtained at the end of the process. (c) Viability of the isolated cells. (d) Remaining erythrocytes before the lysis step. The box contains the middle $50 \%$ of the data, with the upper edge indicating the 75 th percentile of the data set and the lower edge indicating the 25 th percentile. The line in the box indicates the median value of the data.

method. Results are presented as fold increase relative to control sample except for TERT quantification which was done using RT dilution as standard and results expressed as relative arbitrary units.

2.7. Practicability. Pros and cons for each method were noticed during the process.

2.8. Statistical Analysis. Data are presented as mean \pm standard error of the mean (SEM). Each experiment has been performed to reach at least three repetitions $(n \geq 3)$. Differences were considered statistically significant by use of Kruskal-Wallis for multiple samples followed by Dunn's multiple comparisons test if they attained $p<0.05$ (Prism, v4, GraphPad Software, Inc., La Jolla, CA, USA).

\section{Results}

3.1. Tissue Processing Time. Routine method allows the SVF isolation in more than 150 minutes, when Stem.pras process took about 110 minutes. Puregraft permitted the cell extraction in around 100 minutes and our GID-SVF1 allowed us to isolate SVF in approximatively 90 minutes.

3.2. SVF Cell Yield. The quantity of fat harvested (Figure 2(a)), the total viable nucleated cells (Figure 2(b)), the viability of harvested cells (Figure 2(c)), and the remaining erythrocytes before the red blood cell lysis (Figure 2(d)) are shown in Figure 2. Globally, there are no significant differences regarding the parameters assessed. Indeed, the average quantity of dry adipose tissue obtained after the 
washing steps was $76 \pm 15.53,96.5 \pm 18.68,98.5 \pm 17.56$, and $107.25 \pm 11.29$ grams, respectively, for the reference method, GID-SVF1, Puregraft, and Stem.pras, respectively (Figure 2(a); $p=0.5247)$. No statistical difference was found in the yields of SVF cell isolation obtained from the four methods used in this study (Figure 2(b); $p=0.2420$ ). Indeed, $0.795 \pm 0.228,0.425 \pm 0.047,0.25 \pm 0.07$, and $0.535 \pm 0.209 \times$ $10^{6}$ total nucleated cells per gram of dry fat were recovered from reference method, GID-SVF1, Puregraft, and Stem.pras, respectively. The mean viability of TNC was $75.8 \% \pm 4.23$, $81.47 \% \pm 1.44,77.45 \% \pm 1.06$, and $69.3 \% \pm 2.41$ when isolated using reference method, GID-SVF1, Puregraft, and Stem.pras, respectively (Figure 2(c), $p=0.6925$ ). The number of remaining erythrocytes was determined before the red blood cell lysis buffer incubation and was $26.43 \pm 8.3,5.83 \pm$ $1.23,5.85 \pm 1.75$, and $11.88 \pm 3.32 \times 10^{6}$ per gram of dry fat when the SVF was obtained with reference method, GIDSVF1, Puregraft, and Stem.pras, respectively (Figure 2(d), $p=$ $0.6933)$.

\subsection{Cultured ASC Characteristics}

3.3.1. Phenotype. SVF cells and P0 ASC and P1 ASC immunophenotypes were determined using flow cytometry and the results are displayed in Figure 3. The gating strategy was designed in order to exclude debris and doublets or aggregates (Figure 3(a)). For SVF analysis (Figure 3(b)), for all molecules screened, cells were not significantly different except for CD90 marker in Stem.pras isolated SVF cells when compared with GID-SVF1 and reference method but not with Puregraft $(p<0.01$ and $p<0.05$, resp.; $p>0.05$ when compared with Puregraft). Classical CD73 mesenchymal marker and HLA-ABC were not statistically different between the devices $(p>0.05)$. In the same way, hematopoietic markers CD14, CD45, and HLA-DR were expressed at the same level in SVF $(p>0.05)$. Whatever the technique and medical device, expanded cells show the same phenotype as determined by flow cytometry. For P0 and P1 immunophenotype, the cells harbored a mesenchymal phenotype as shown in Figure 3(c) for P0 and Figure 3(d) for P1. Indeed, all the cells analyzed expressed CD90 and CD73 mesenchymal protein and HLA-ABC,and lacked the expression of CD14, CD45, and HLA-DR hematopoieticrelated markers. Finally, cell expansion induced a dramatic decrease of CD34 expression from around 70\% in the SVF to less than $10 \%$ on the surface of the cells at passage 1 .

3.3.2. Proliferation Potential. Growth results of cultured cells from the four methods did not show any statistical differences as shown in Figure 4. Indeed, to compare the cell proliferation potential related to each medical device, cells were plated at 4,000 cells $/ \mathrm{cm}^{2}$ and grown in proliferation medium for two subcultures. As shown in Figures 4(a) and 4(b), we did not find any statistical differences in the population doublings (PD), and thus cumulative PD and doubling times (DT) (see material and methods section for detailed calculation) were evaluated at the end of the culture. PD at the first (P1) and the second subculture $(\mathrm{P} 2)$ were almost the same $(p=0.9363$ and $p=0.8697$, resp.) as the resulting $\mathrm{CPD}$ were $p=0.4753$.
Moreover, to explore the clonogenic potential of SVF cells, we plated the cells at very low density (i.e., 40 cells $/ \mathrm{cm}^{2}$ ), and evaluated their colony forming efficiency (CFE, Figure 4(c)). Reference method and GID-SVF1 methods allow isolating cells with the same apparent CFE $(p>0.05)$, as Puregraft and Stem.pras do $(p>0.05)$. However, reference method and GID-SVF1 were greater in obtaining clonogenic cells than Puregraft and Stem.pras $(p<0.001)$, as shown in Figure 4(d).

3.3.3. Genetic Stability. None of the methods used in this study gave rise to genetically unstable cells, at least in regard to their karyotype (Figure 4(e)) and TERT expression (Figure 4(f)). Indeed, in order to check the possible genetic abnormalities of the ex vivo expanded cells, we carried out karyotyping analysis. No chromosomal modifications were observed in our culture condition, for every cells from all the devices used in this study (Figure 4(e)). We then also performed RT-qPCR experiments to verify the absence of expression of TERT mRNA (Figure 4(f)). Our results show the expression of TERT mRNA in MRC5-TERT cell line, while no expression was observed in untransfected MRC5 cell line and in our cells (Figure 4(f)).

3.3.4. Multilineage Differentiation. To establish whether the cells obtained from the four methods were able to differentiate toward the three recommended lineages [11, 13], we exposed ASC at passage 1 to adipogenic, osteogenic, and chondrogenic medium. All the cell lines were able to differentiate to these mesodermal lineages (Figure 5). Oil Red O, Alizarin Red, and Alcian Blue staining were strongly positive using induction medium compared control condition for adipo-, osteo-, and chondrogenic differentiation, respectively. No significant differences were observed in specific genes for each differentiation assay ( $p>0.05$, Kruskal-Wallis).

3.4. Practicability of the Devices. All the devices evaluated allow an improvement of the process compared to the reference method. Indeed, GID SVF-1 and Stem.pras permit the harvest of lipoaspirated fat directly into the device. Puregraft was collected in an intermediate sterile container and then transferred into the bag using a Toomey syringe. Furthermore, GID-SVF1 and Stem.pras allow performing all the steps of the isolation process straight into the device, in a fully closed manner. GID-SVF1 is provided with its proprietary enzyme mixture, GIDzyme-2, as a ready-to-use device.

\section{Discussion}

The SVF and ASC bear great therapeutic potential in wide variety of reconstructive and regenerative applications [3034]. Nevertheless, their use may be restricted by the challenges regarding their production as clinical grade products. Indeed, skilled staff, isolation duration, and logistic obstacle can hamper the viability, sterility, consistency, and functionality of the cell preparation. Mastering these hurdles is a hard goal to reach, and semiautomated devices for cell isolation are a crucial way to overcome these obstacles. 

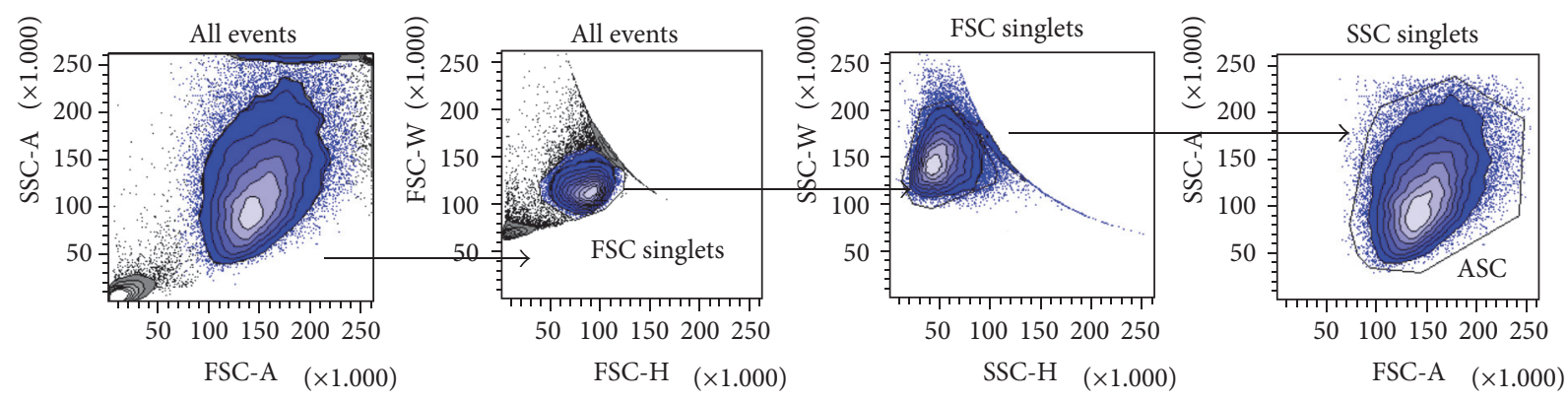

(a)

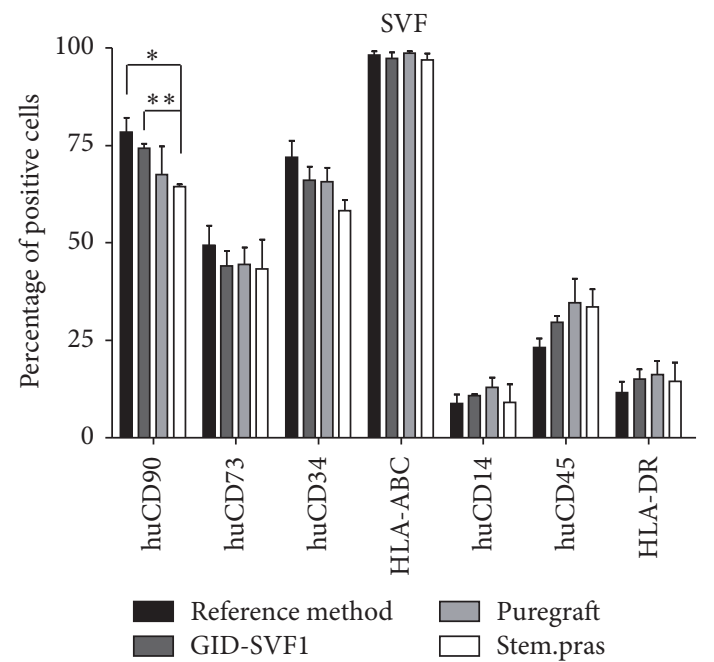

(b)

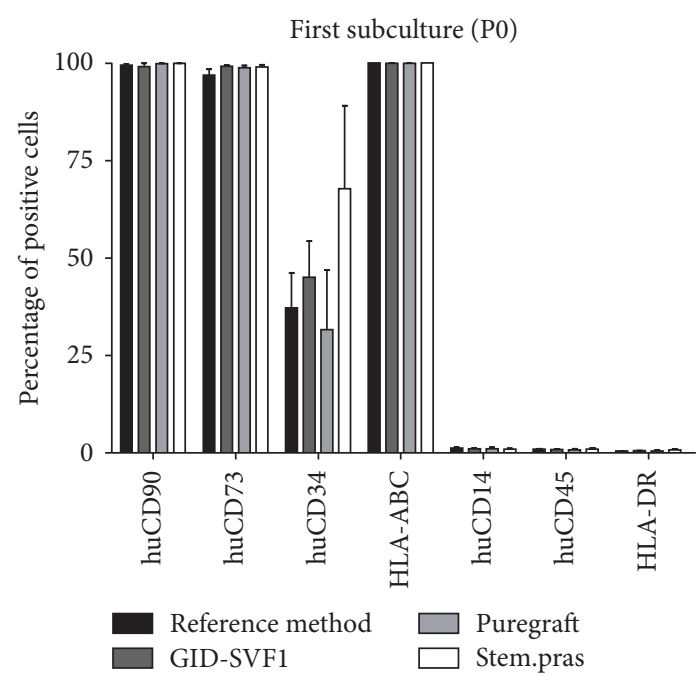

(c)

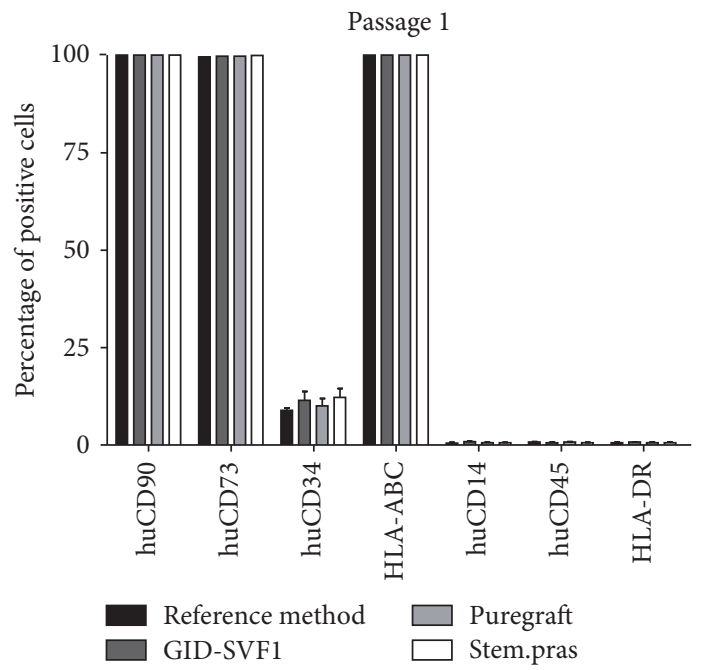

(d)

FIGURE 3: Detection of cell surface markers expressed by SVF cells and ASC at passages 0 and 1 by immunophenotyping and flow-cytometric analysis. (a) Gating strategy stream on morphological forward (FSC) and side scatter (SSC) used to eliminate debris and selected for cultured hASCs represented by contour plot. (b) Immunophenotyping of SVF cells. (c) Immunophenotyping of ASC at the first subculture (P0). (d) Immunophenotyping of ASC at the second subculture (P1). ${ }^{*} p<0.05 ;{ }^{* *} p<0.01$.

According to our defined criteria, the three evaluated devices, GID-SVF1 CE-labeled for SVF isolation, Puregraft firstly designed to wash and filter AT, and Stem.pras in current development for SVF isolation were validated for
SVF extraction in operating room as well as for ASC culture in GMP facilities because no significant results were found versus the reference method. Indeed, regarding the SVF isolation, the devices are less time-consuming than reference 


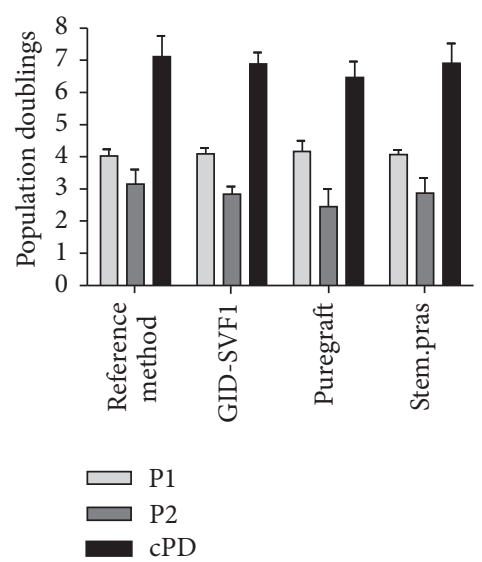

(a)

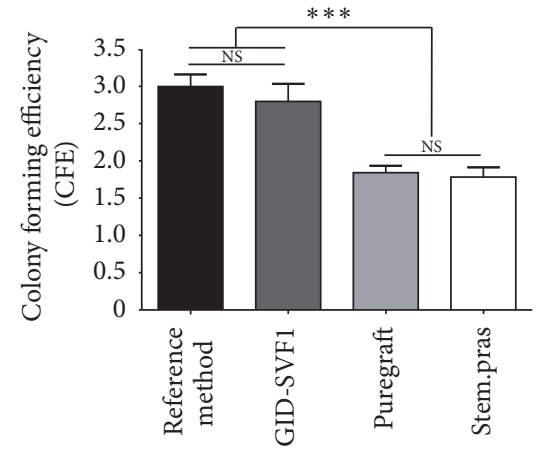

(d)
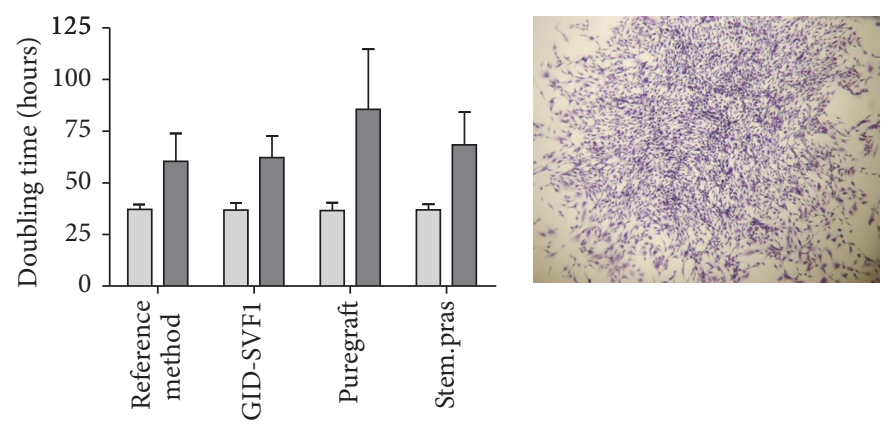

$\square \mathrm{P} 1$ (b)

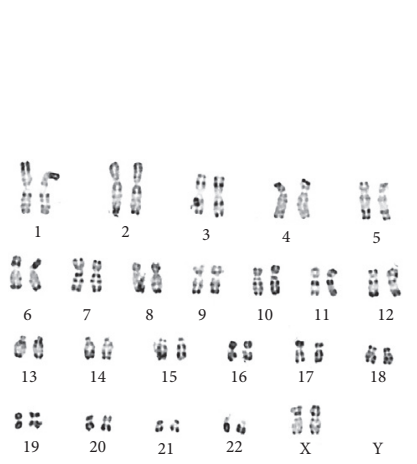

(e) (c)

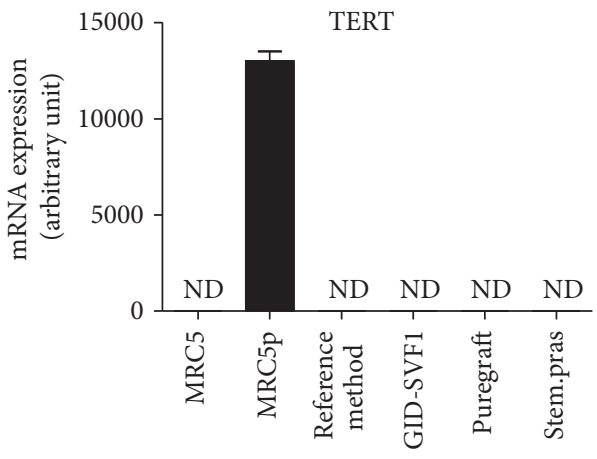

(f)

FIgURE 4: Growth kinetics and clonogenic potential of cells obtained with the four methods. (a) Population doubling (PD) at passages 1 and 2 and the corresponding cumulative PD for the four methods used to obtain the SVF. (b) Doubling time in hours for each subculture. (c) Representative photograph of a clone for CFU assay. (d) Colony forming efficiency calculated based on CFU assay. (e) All cell lines showed a normal karyotype with 23 chromosomes pairs and G-banding, indicating no chromosomal aberrations. (The karyotype shown is representative of the four methods evaluated.) (f) No hTERT expression was detected in the cell lines tested while positive control MRC5p hTERT-transfected cell line showed a high expression. CFE, colony forming efficiency; ND, not detected; NS, not significant. ${ }^{* * *} p<0.001$.

method which take more than 150 minutes, whereas GIDSVF1, Puregraft, and Stem.pras need only 90, 100, and 110 minutes, respectively. These outcomes regarding process time are consistent with those found in the literature related to enzymatic digestion of lipoaspirated adipose tissue $[8,10,35]$. Furthermore, GID-SVF1 and Stem.pras allow the fat harvest, washing, and digestion in a closed manner, whereas reference method is a fully open process. In the case of Puregraft, it will be possible to harvest the lipoaspirated fat straight within the bag by using the Fat Lock ${ }^{\mathrm{TM}}$ system (commercially available from BE NEW Medical). However, this new system implies the fat suction with a syringe and cannot be used with a vacuum pump. Moreover, they permit reaching a cell yield upper than $2.5 \times 10^{5}$ cells/gram of dry AT (from $2.5 \times 10^{5} \pm$ 0.07 to $7.95 \times 10^{5} \pm 0.21$ ) with viability greater than $69 \%$ (from $69.3 \pm 2.4$ to $81.46 \pm 1.4$ ) which is also consistent with already published data $[8,35,36]$. Finally, SVF cells show a high CD34 and CD90 and a weak CD45 proportion, a frequency of CFU-F upper than $1 \%$ and with a trilineage potential. Altogether, our results fulfill the recommendations advised by the ISCT and the International Federation for Adipose Therapeutics (IFATS) [14]. Regarding grown cells obtained from the devices from SVF plating in culture dishes, no karyotype abnormalities and no hTERT expression were shown, thus highlighting a genetic stability.

Furthermore, duration of collagenase digestion has been correlated with poor cell viability [37]. In our design, we set the time of enzymatic treatment to be the same as our reference technique validated in our GMP process in order to reach the best compromise for both cell yield and viability. Regarding collagenase, we set the concentration at $0.1 \mathrm{U} / \mathrm{mL}$ (GMP) to standardize and limit the variability of our process, except for GID-SVF1 in which collagenase is provided in a ready-to-use kit with unknown concentration. The digestion time and concentration of collagenase have been determined previously in our lab (unpublished data). Despite this restriction, our results were not significantly different in terms of the cell yield and viability. The great benefit of these systems when compared with reference method is that they allow (or with slight modification) the harvest of SVF cells in a closed system from the patients to the patient or from patient to culture dishes easily.

Those devices facilitate washing of lipoaspirated fat. Washing steps are crucial to reduce undesirable components, 


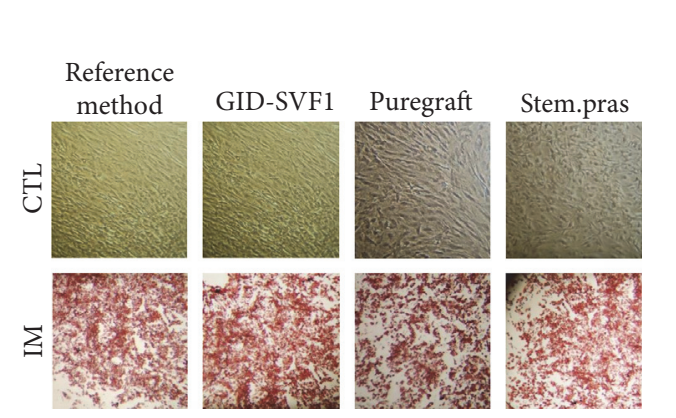

(a)

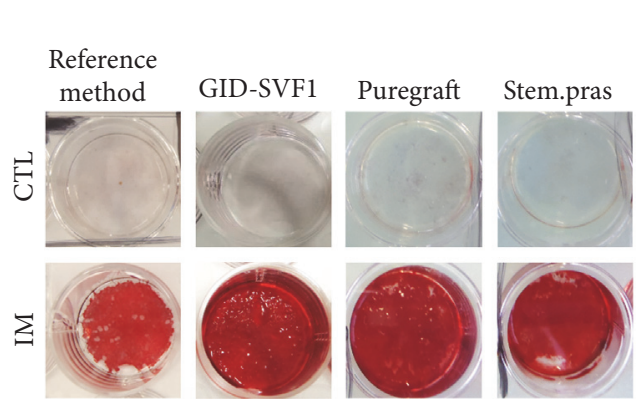

(c)

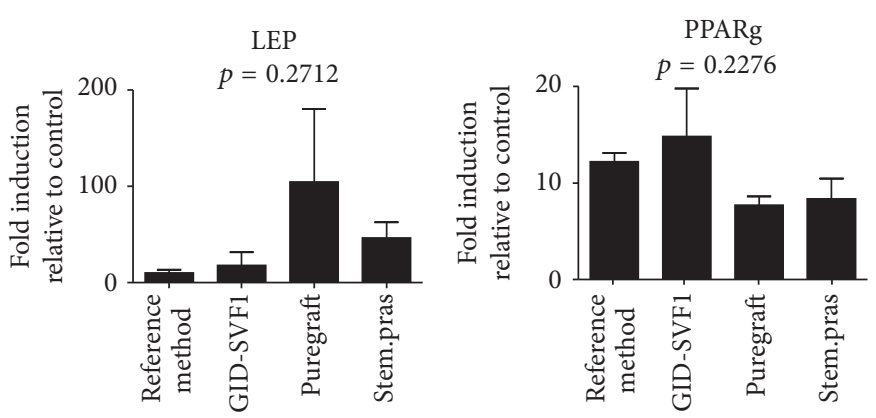

(b)
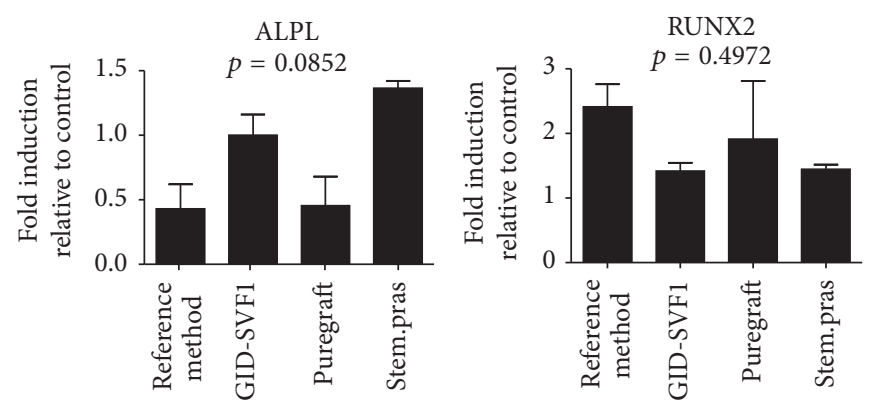

(d)

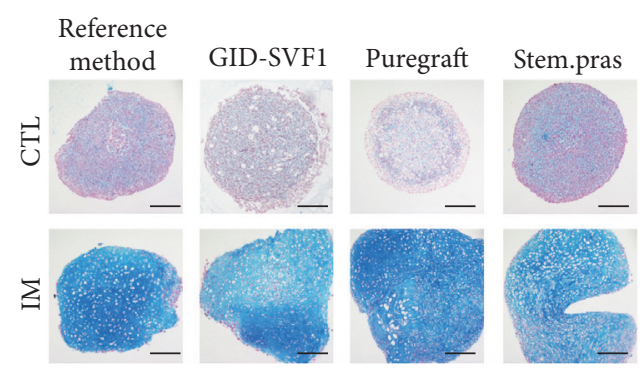

(e)
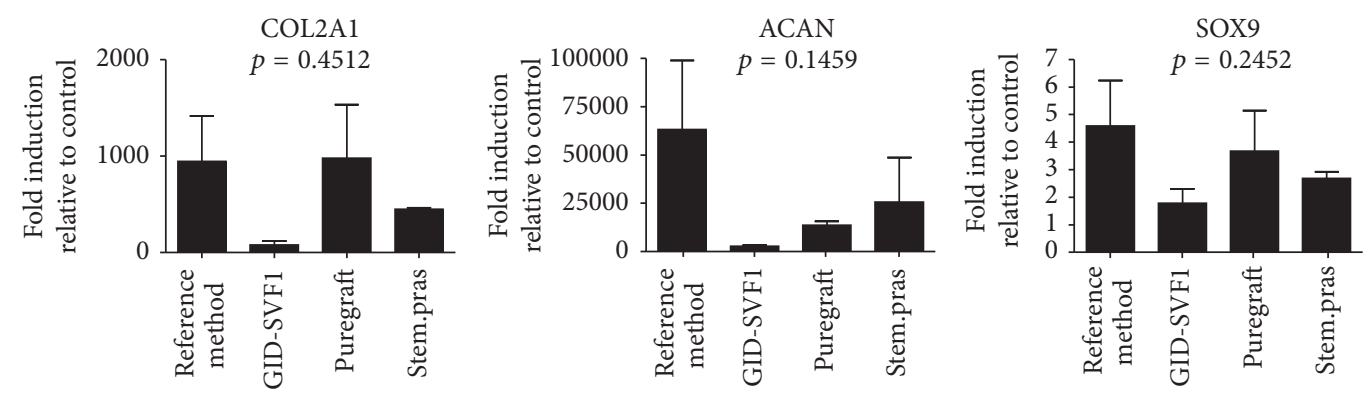

(f)

FIGURE 5: Multilineage differentiation of passage 1 adipose-derived stromal cell isolated using four different methods. (a) Cells either untreated (Ctl) or treated with adipogenic induction medium (IM) for 14 days and stained with Oil Red O. (b) RT-PCR assay for leptin and PPARG adipogenic specific genes. (c) Cells either untreated (Ctl) or treated with osteogenic induction medium (IM) for 21 days and stained with Alizarin Red. (d) RT-PCR assay for ALPL and RUNX2 osteogenic specific genes. (e) Cells either untreated (Ctl) or treated with chondrogenic induction medium (IM) for 21 days and stained with Alcian Blue. Scale bar $200 \mu \mathrm{m}$. (f) RT-PCR assay for COL2A1, ACAN, and SOX9 chondrogenic specific genes.

such as blood, debris, free lipid, and ruptured adipocytes, while retaining viable adipose tissue for further use. The most common release criteria value for cell viability is upper $70 \%$ [14]. On average, all the devices tested in this study meet this crucial criterion. However, two of the values only for
Stem.pras were under 70\%. In our hands, the four methods are similar regarding their washing efficacy since we did not show any statistical difference in the remaining erythrocytes in the SVF. The presence of red blood cells in the SVF in the context of its use for ASC expansion is not a major issue since 
these contaminants are not adherents and are removed from the culture dish by the medium change after one hour in our protocol.

Regarding the immunophenotype, whatever the devices used, more than $64 \%$ and more than $43 \%$ of the isolated cells expressed mesenchymal markers CD90 and CD73, respectively, and more than $58 \%$ expressed putative ASC CD34 molecule $[14,38]$. However, it would be of great interest to perform multiparametric flow cytometry in order to highlight the exact proportion of native ASC in the SVF as they are defined by the expression of CD34 and the associated lack of CD31 endothelial marker and CD45 pan-leukocyte markers. Furthermore, CD34 native ASC phenotype has been shown to disappear during cell expansion, an observation that we confirm in our results. In our point of view, monochromatic flow cytometry should be considered as sufficient for the screening of classical markers of ASC since these molecules have an "ON/OFF" expression pattern on cultured ASC from two or three subcultures $[39,40]$. Moreover, our results show that our grown cells, whatever the device, harbor the mesenchymal recommended phenotype [13].

In vitro and under specific stimuli, ASCs have been shown to have a wide multipotency [41]. Here we show that our cells are able to differentiate toward adipogenic, osteogenic, and chondrogenic lineages with no significant differences regarding gene specific expression. In a previous study from our team, we demonstrate the ability of ASC to engage toward endothelial lineage [12].

In the context of ATMP manufacturing after cell expansion, it is crucial to verify the genetic stability [42-44]. Our results did not show any genetic instability using karyotyping and TERT mRNA was not detectable as determined by RTqPCR approach. Transformation process is a complicated sequence of events which might occur when the cells are grown in vitro $[45,46]$. Nowadays, there is no evidence of a real genetic instability of ASC and MSC in general [47], but a small number of publications highlighted few aberrations [48, 49], and some publications [50, 51] have been retracted due to cell culture contamination [52, 53]. Moreover, we deeply think that closed system that strikingly limit the microbial contamination allow surgical unit and GMPlaboratories to preserve the safety of the patient.

Regarding the quality controls and the conformity to the regulation, all methods described in this study match the recommendations. Consequently, all of them can be used and chosen depending on their availability in the country or their cost, for example. Regarding the practicability, GIDSVF1 appears to be the most appropriate device for a surgeon in an operating room as it is provided as a ready-to-use kit including the collagenase. A new version of this device, the GID-SVF2 ${ }^{\mathrm{TM}}$ has recently been compared to other devices [35]. Even if it has to be confirmed, it appears that this new version is smaller and yield less TNC and CFU than the GID-SVF1 tested in this study. From the same point of view, Proteal could improve its Stem.pras system simply by adding a ready-to-use collagenase. Puregraft is already used in operating room for autologous fat transfer [54] and, thanks to our results, surgeons could use this tool to perform CAL. Similarly, Puregraft could be improved by adding a ready-to-use collagenase. Finally, GID-SVF1, Stem.pras, and Puregraft system are suitable for cell therapy labs equipped with GMP facilities.

Nevertheless, it is possible to obtain ASC without the use of any device, as published for the explanted lipoaspirate or adipose tissue [55]. These approaches allow efficiently obtaining ASC, in a more economic and faster manner, but the techniques we present in this paper bring the close processing of the tissue. Even if we did not test the sterility of the SVF obtained from each devices, this aspect is of great interest because it maximizes the probability to obtain a sterile SVF. Nevertheless, none of the SVF seeded showed any microbiological development in vitro. Lastly, a number of papers report the absence of residual collagenase activity in their final products $[8,35]$. In 2013 , it has been reported that there was no detectable residual collagenase activity after the first wash. In our study, we use a low collagenase concentration $(0.1 \mathrm{U} / \mathrm{mL})$, and we performed 2 washing steps which altogether allow presumably the lowering of the residual collagenase activity to an undetectable level.

The SVF isolation devices market is expanding for many years, and it is obviously important to check their efficacy before the transfer from bench to bedside.

Our results clearly demonstrate that the three evaluated closed devices, GID-SVF1, Puregraft, and Stem.pras, are equivalent to reference method in terms of SVF cells yield, viability, phenotype, and clonogenic potential. We also found that their expanded cells are similar in terms of phenotype, proliferation potential, multipotency, and genetic stability.

\section{Competing Interests}

The authors declare that they have no competing interests.

\section{Authors' Contributions}

Jonathan Rodriguez contributed to conception and design, collection and/or assembly of data, data analysis and interpretation, manuscript writing and revision, and final approval of manuscript. Anne-Sophie Pratta assisted in conception and design, collection and/or assembly of data, and final approval of manuscript. Nacira Abbassi helped in conception and design, collection and/or assembly of data, and final approval of manuscript. Hugo Fabre contributed to collection and/or assembly of data and final approval of manuscript. Cyrille Debard assisted in collection and/or assembly of data and final approval of manuscript. Jacqueline Adobati helped in collection and/or assembly of data and final approval of manuscript. Fabien Boucher assisted in conception and design, provision of study material or patients, collection and/or assembly of data, data analysis and interpretation, and final approval of manuscript. Frédéric Mallein-Gerin helped in collection and/or assembly of data and final approval of manuscript. Céline Auxenfans contributed to collection and/or assembly of data and final approval of manuscript. Odile Damour contributed to conception and design, data analysis and interpretation, manuscript writing and revision, and final approval of manuscript. Ali Mojallal assisted 
in conception and design, provision of study material or patients, data analysis and interpretation, manuscript writing and revision, and final approval of manuscript.

\section{Acknowledgments}

The authors acknowledge the contribution of the CelluloNet BioBank of UMS3444/US8/SFR Biosciences. They would like to thank the IHU OPeRa for funding ASC development and the Hospices Civils de Lyon (HCL) for giving us permission to carry out this study. They would like to thank Eurosilicone, Proteal, and the GID Group Inc. for the providing of Puregraft, Stem.pras, and GID-SVF1, respectively.

\section{References}

[1] J. Smahel, "Adipose tissue in plastic surgery," Annals of Plastic Surgery, vol. 16, no. 5, pp. 444-453, 1986.

[2] A. Mojallal and J.-L. Foyatier, "Historical review of the use of adipose tissue transfer in plastic and reconstructive surgery," Annales de Chirurgie Plastique et Esthétique, vol. 49, no. 5, pp. 419-425, 2004

[3] P. A. Zuk, M. Zhu, P. Ashiian et al., "Human adipose tissue is a source of multipotent stem cells," Molecular Biology of the Cell, vol. 13, no. 12, pp. 4279-4295, 2002.

[4] P. A. Zuk, M. Zhu, H. Mizuno et al., "Multilineage cells from human adipose tissue: implications for cell-based therapies," Tissue Engineering, vol. 7, no. 2, pp. 211-228, 2001.

[5] D. Matsumoto, K. Sato, K. Gonda et al., "Cell-assisted lipotransfer: supportive use of human adipose-derived cells for soft tissue augmentation with lipoinjection," Tissue Engineering, vol. 12, no. 12, pp. 3375-3382, 2006.

[6] A. Sterodimas, J. de Faria, B. Nicaretta, O. Papadopoulos, E. Papalambros, and Y. G. Illouz, "Cell-assisted lipotransfer," Aesthetic Surgery Journal, vol. 30, no. 1, pp. 78-81, 2010.

[7] K. Yoshimura, K. Sato, N. Aoi, M. Kurita, T. Hirohi, and K. Harii, "Cell-assisted lipotransfer for cosmetic breast augmentation: supportive use of adipose-derived stem/stromal cells," Aesthetic Plastic Surgery, vol. 32, no. 1, pp. 48-55, 2008.

[8] J. A. Aronowitz and J. D. I. Ellenhorn, "Adipose stromal vascular fraction isolation: a head-to-head comparison of four commercial cell separation systems," Plastic and Reconstructive Surgery, vol. 132, no. 6, pp. 932e-939e, 2013.

[9] K. Doi, S. Tanaka, H. Iida et al., "Stromal vascular fraction isolated from lipo-aspirates using an automated processing system: bench and bed analysis: SVF from lipoaspirates using automated processing," Journal of Tissue Engineering and Regenerative Medicine, vol. 7, pp. 864-870, 2013.

[10] E. Raposio, G. Caruana, M. Petrella, S. Bonomini, and M. P. Grieco, "A standardized method of isolating adipose-derived stem cells for clinical applications," Annals of Plastic Surgery, vol. 76, no. 1, pp. 124-126, 2016.

[11] M. F. Pittenger, "Multilineage potential of adult human mesenchymal stem cells," Science, vol. 284, pp. 143-147, 1999.

[12] C. Auxenfans, C. Lequeux, E. Perrusel, A. Mojallal, B. Kinikoglu, and O. Damour, "Adipose-derived stem cells (ASCs) as a source of endothelial cells in the reconstruction of endothelialized skin equivalents," Journal of Tissue Engineering and Regenerative Medicine, vol. 6, no. 7, pp. 512-518, 2012.

[13] M. Dominici, K. Le Blanc, I. Mueller et al., "Minimal criteria for defining multipotent mesenchymal stromal cells. The
International Society for Cellular Therapy position statement," Cytotherapy, vol. 8, no. 4, pp. 315-317, 2006.

[14] P. Bourin, B. A. Bunnell, L. Casteilla et al., "Stromal cells from the adipose tissue-derived stromal vascular fraction and culture expanded adipose tissue-derived stromal/stem cells: a joint statement of the International Federation for Adipose Therapeutics and Science (IFATS) and the International Society for Cellular Therapy (ISCT)," Cytotherapy, vol. 15, no. 6, pp. 641648, 2013.

[15] W. U. Hassan, U. Greiser, and W. Wang, "Role of adiposederived stem cells in wound healing," Wound Repair and Regeneration, vol. 22, no. 3, pp. 313-325, 2014.

[16] J. Rodriguez, F. Boucher, C. Lequeux et al., "Intradermal injection of human adipose-derived stem cells accelerates skin wound healing in nude mice," Stem Cell Research and Therapy, vol. 6, article 241, 2015.

[17] B. Granel, A. Daumas, E. Jouve et al., "Safety, tolerability and potential efficacy of injection of autologous adipose-derived stromal vascular fraction in the fingers of patients with systemic sclerosis: an open-label phase I trial," Annals of the Rheumatic Diseases, vol. 74, no. 12, pp. 2175-2182, 2015.

[18] P. Guillaume-Jugnot, A. Daumas, J. Magalon et al., "Autologous adipose-derived stromal vascular fraction in patients with systemic sclerosis: 12-month follow-up," Rheumatology, vol. 55, no. 2, pp. 301-306, 2016.

[19] M. Ruiz, S. Cosenza, M. Maumus, C. Jorgensen, and D. Noël, "Therapeutic application of mesenchymal stem cells in osteoarthritis," Expert Opinion on Biological Therapy, vol. 16, no. 1, pp. 33-42, 2016.

[20] D. You, M. J. Jang, B. H. Kim et al., "Comparative study of autologous stromal vascular fraction and adipose-derived stem cells for erectile function recovery in a rat model of cavernous nerve injury," Stem Cells Translational Medicine, vol. 4, no. 4, pp. 351$-358,2015$.

[21] N. H. Riordan, T. E. Ichim, W.-P. Min et al., "Non-expanded adipose stromal vascular fraction cell therapy for multiple sclerosis," Journal of Translational Medicine, vol. 7, article 29, 2009.

[22] X. Matillon, E. Baulier, T. Hauet et al., "Characterization of mesenchymal stem cells from pig fat and their effect on delayed graft function of transplanted kidney in a preclinical pig model of auto-transplantation mimicking the non-heartbeating donors conditions," Progres en Urologie, vol. 25, article 763, 2015.

[23] M. Zhu, S. R. Cohen, K. C. Hicok et al., "Comparison of three different fat graft preparation methods: gravity separation, centrifugation, and simultaneous washing with filtration in a closed system," Plastic and Reconstructive Surgery, vol. 131, no. 4, pp. 873-880, 2013.

[24] S. Dos-Anjos Vilaboa, M. Navarro-Palou, and R. Llull, "Age influence on stromal vascular fraction cell yield obtained from human lipoaspirates," Cytotherapy, vol. 16, no. 8, pp. 1092-1097, 2014.

[25] B. Johnstone, T. M. Hering, A. I. Caplan, V. M. Goldberg, and J. U. Yoo, "In vitro chondrogenesis of bone marrow-derived mesenchymal progenitor cells," Experimental Cell Research, vol. 238, no. 1, pp. 265-272, 1998.

[26] T. Fink, P. Lund, L. Pilgaard, J. G. Rasmussen, M. Duroux, and V. Zachar, "Instability of standard PCR reference genes in adipose-derived stem cells during propagation, differentiation and hypoxic exposure," BMC Molecular Biology, vol. 9, article 98, 2008. 
[27] J. Tratwal, B. Follin, A. Ekblond, J. Kastrup, and M. HaackSørensen, "Identification of a common reference gene pair for qPCR in human mesenchymal stromal cells from different tissue sources treated with VEGF," BMC Molecular Biology, vol. 15, article 11, 2014.

[28] L. C. Rose, D. K. Kadayakkara, G. Wang et al., "Fluorine-19 labeling of stromal vascular fraction cells for clinical imaging applications," Stem Cells Translational Medicine, vol. 4, no. 12, pp. 1472-1481, 2015.

[29] S. Güven, M. Karagianni, M. Schwalbe et al., "Validation of an automated procedure to isolate human adipose tissue-derived cells by using the sepax ${ }^{\circledR}$ technology," Tissue Engineering Part C: Methods, vol. 18, no. 8, pp. 575-582, 2012.

[30] S. A. Brown, B. Levi, C. Lequex, V. W. Wong, A. Mojallal, and M. T. Longaker, "Basic science review on adipose tissue for clinicians," Plastic and Reconstructive Surgery, vol. 126, no. 6, pp. 1936-1946, 2010.

[31] M. Mendicino, A. M. Bailey, K. Wonnacott, R. K. Puri, and S. R. Bauer, "MSC-based product characterization for clinical trials: an FDA perspective," Cell Stem Cell, vol. 14, no. 2, pp. 141-145, 2014.

[32] R. C. Nordberg and E. G. Loboa, "Our fat future: translating adipose stem cell therapy," Stem Cells Translational Medicine, vol. 4, no. 9, pp. 974-979, 2015.

[33] H. K. Salem and C. Thiemermann, "Mesenchymal stromal cells: current understanding and clinical status," STEM CELLS, vol. 28, no. 3, pp. 585-596, 2010.

[34] M. Tremp, S. Salemi, R. Gobet, T. Sulser, and D. Eberli, "Adipose-Derived Stem Cells (ASCs) for tissue engineering," in Regenerative Medicine and Tissue Engineering-Cells and Biomaterials, InTech, 2011.

[35] J. A. Aronowitz, R. A. Lockhart, C. S. Hakakian, and Z. E. Birnbaum, "Adipose stromal vascular fraction isolation: a head-tohead comparison of 4 cell separation systems \#2," Annals of Plastic Surgery, vol. 77, no. 3, pp. 354-362, 2016.

[36] C. F. Markarian, G. Z. Frey, M. D. Silveira et al., "Isolation of adipose-derived stem cells: a comparison among different methods," Biotechnology Letters, vol. 36, no. 4, pp. 693-702, 2014.

[37] S. A. Seaman, S. C. Tannan, Y. Cao, S. M. Peirce, and K. Y. Lin, "Differential effects of processing time and duration of collagenase digestion on human and murine fat grafts," Plastic and Reconstructive Surgery, vol. 136, no. 2, pp. 189e-199e, 2015.

[38] M. Maumus, J.-A. Peyrafitte, R. D’Angelo et al., "Native human adipose stromal cells: localization, morphology and phenotype," International Journal of Obesity, vol. 35, no. 9, pp. 1141-1153, 2011.

[39] G. Pachón-Peña, G. Yu, A. Tucker et al., "Stromal stem cells from adipose tissue and bone marrow of age-matched female donors display distinct immunophenotypic profiles," Journal of Cellular Physiology, vol. 226, no. 3, pp. 843-851, 2011.

[40] K. Yoshimura, T. Shigeura, D. Matsumoto et al., "Characterization of freshly isolated and cultured cells derived from the fatty and fluid portions of liposuction aspirates," Journal of Cellular Physiology, vol. 208, no. 1, pp. 64-76, 2006.

[41] J. M. Gimble and F. Guilak, "Differentiation potential of Adipose Derived Adult Stem (ADAS) cells," Current Topics in Developmental Biology, vol. 58, pp. 137-160, 2003.

[42] C. E. P. Goldring, P. A. Duffy, N. Benvenisty et al., "Assessing the safety of stem cell therapeutics," Cell Stem Cell, vol. 8, no. 6, pp. 618-628, 2011.
[43] J. A. Heslop, T. G. Hammond, I. Santeramo et al., "Concise review: workshop review: understanding and assessing the risks of stem cell-based therapies," Stem Cells Translational Medicine, vol. 4, no. 4, pp. 389-400, 2015.

[44] L. Sensebé, "Beyond genetic stability of mesenchymal stromal cells," Cytotherapy, vol. 15, no. 11, pp. 1307-1308, 2013.

[45] M. Chow and H. Rubin, "Clonal selection versus genetic instability as the driving force in neoplastic transformation," Cancer Research, vol. 60, no. 22, pp. 6510-6518, 2000.

[46] L. Hayflick and P. S. Moorhead, "The serial cultivation of human diploid cell strains," Experimental Cell Research, vol. 25, no. 3, pp. 585-621, 1961.

[47] S. Sharma and R. Bhonde, "Mesenchymal stromal cells are genetically stable under a hostile in vivo-like scenario as revealed by in vitro micronucleus test," Cytotherapy, vol.17, no. 10, pp. 13841395, 2015.

[48] N. Bigot, A. Mouche, M. Preti et al., "Hypoxia differentially modulates the genomic stability of clinical-grade ADSCs and BM-MSCs in long-term culture," STEM CELLS, vol. 33, no. 12, pp. 3608-3620, 2015.

[49] O. A. Buyanovskaya, N. P. Kuleshov, V. A. Nikitina, E. S. Voronina, L. D. Katosova, and N. P. Bochkov, "Spontaneous aneuploidy and clone formation in adipose tissue stem cells during different periods of culturing," Bulletin of Experimental Biology and Medicine, vol. 148, no. 1, pp. 109-112, 2009.

[50] G. V. Røsland, A. Svendsen, A. Torsvik et al., "Long-term cultures of bone marrow-derived human mesenchymal stem cells frequently undergo spontaneous malignant transformation," Cancer Research, vol. 69, no. 13, pp. 5331-5339, 2009.

[51] D. Rubio, J. Garcia-Castro, M. C. Martín et al., "Spontaneous human adult stem cell transformation," Cancer Research, vol. 65, no. 8, pp. 3035-3039, 2005.

[52] S. Garcia, M. C. Martín, R. de la Fuente, J. C. Cigudosa, J. GarciaCastro, and A. Bernad, "Pitfalls in spontaneous in vitro transformation of human mesenchymal stem cells," Experimental Cell Research, vol. 316, no. 9, pp. 1648-1650, 2010.

[53] A. Torsvik, G. V. Røsland, A. Svendsen et al., "Spontaneous malignant transformation of human mesenchymal stem cells reflects cross-contamination: putting the research field on track-letter," Cancer Research, vol. 70, no. 15, pp. 6393-6396, 2010.

[54] O. Mestak, A. Sukop, Y.-S. Hsueh et al., "Centrifugation versus PureGraft for fatgrafting to the breast after breast-conserving therapy," World Journal of Surgical Oncology, vol. 12, article 178, 2014.

[55] N. Priya, S. Sarcar, A. S. Majumdar, and S. Sundarraj, "Explant culture: a simple, reproducible, efficient and economic technique for isolation of mesenchymal stromal cells from human adipose tissue and lipoaspirate," Journal of Tissue Engineering and Regenerative Medicine, vol. 8, no. 9, pp. 706-716, 2014. 

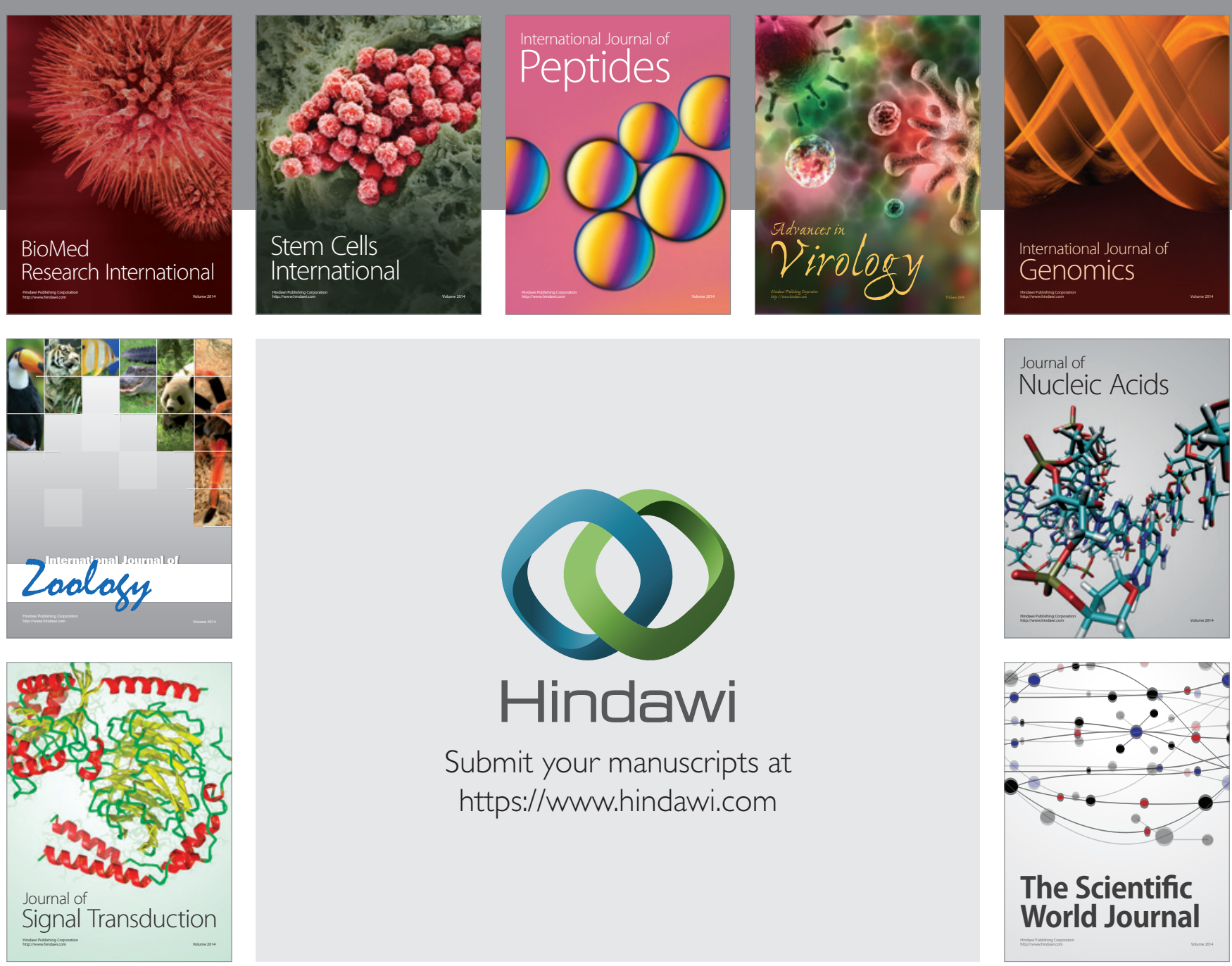

Submit your manuscripts at

https://www.hindawi.com
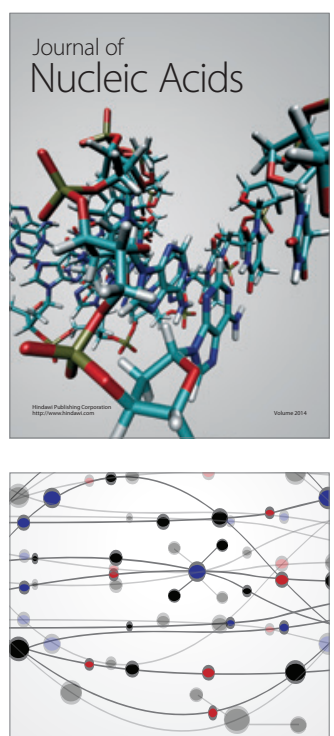

The Scientific World Journal
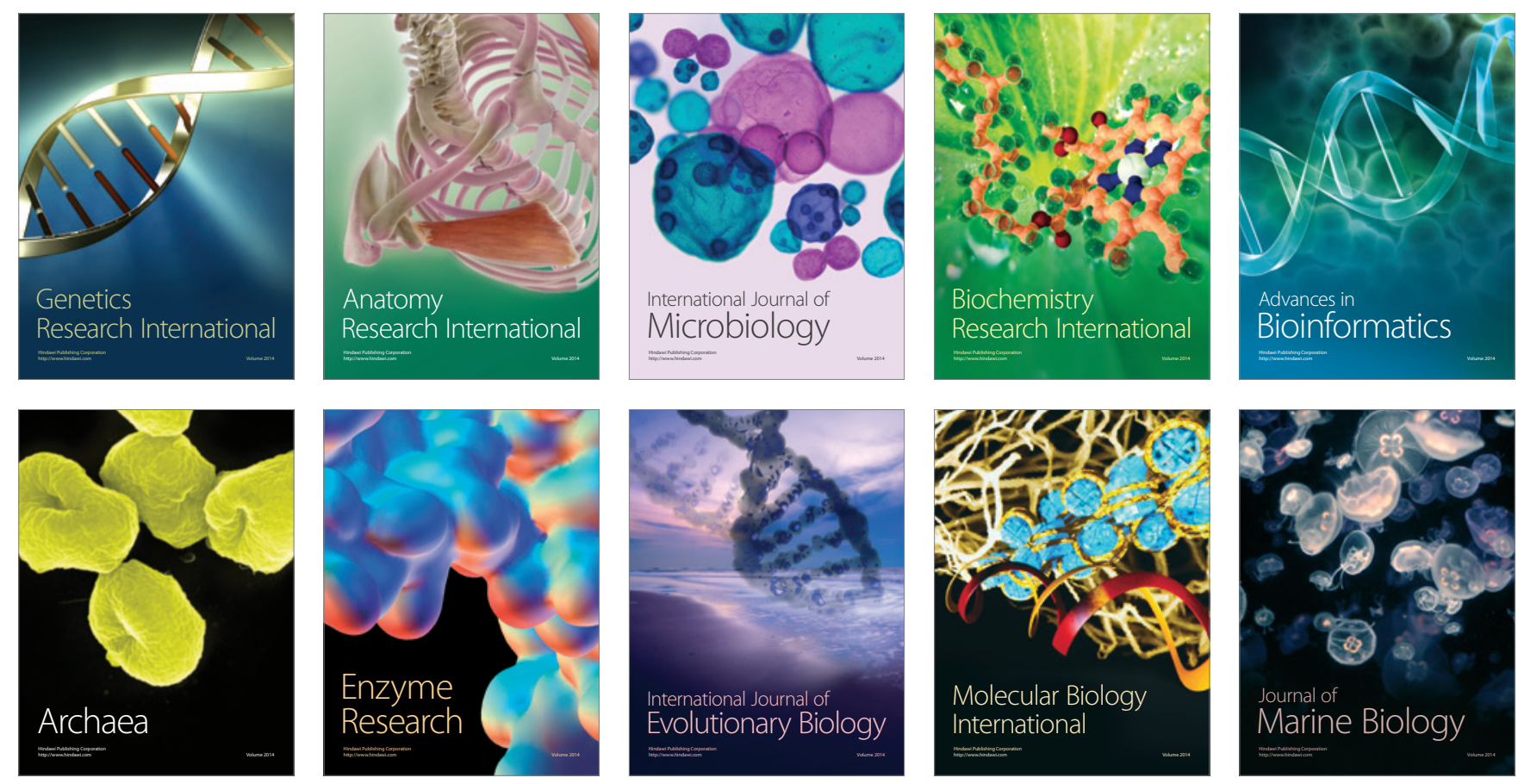